\title{
Linking impact-related progeny sizes of cement clinker to modes of single-particle breakage
}

\author{
Mahmut Camalan ${ }^{1, a}$, and Çetin Hoşten ${ }^{1}$ \\ ${ }^{1}$ Department of Mining Engineering, Middle East Technical University, 06800 Ankara, Turkey
}

\begin{abstract}
Fragmentation of particulate solids is an important process in many industrial activities, particularly in the mineral, cement and glass industries to comminute the raw materials to a required size. Understanding of processes and mechanisms responsible for fragmentation of particulate solids is a hard task. This may bring great precision for designing and controlling the comminution process. This work aims to contribute to understanding fragmentation of cement clinker particles under impact loading. For this purpose, six narrowsize classes of Portland clinker were fragmented with varying specific impact energy levels in a drop weight test apparatus. Then, breakage probabilities and functions of these size classes were determined from the product size distributions. The calculated breakage functions show evidences for the modes of breakage (meridian cracks to oblique cracks and shattering) given in the literature. Results of this study indicate that self-similarity of progeny size distributions can only be achieved, regardless of particle size and impact energy, if the particles have the same breakage probability, that is the same mode of breakage.
\end{abstract}

\section{Introduction}

When a brittle material is subjected to an impact, the resultant mode of breakage is dependent either on the magnitude of the impact energy or the impact velocity. Four modes of breakage have been proposed in this respect: (i) the Hertzian crack system [1-4]; (ii) meridian (diametrical)/secondary cracks [1, 2, 5-10]; (iii) oblique/radial cracks [1, 2, 9]; and (iv) shattering or catastrophic failure [1, 2, 11]. The Hertzian crack system are formed preferentially at low-strain rates, involving the cone and undeveloped ring cracks. Additional increase in the either strain-rate or the impact velocity results in an additional inelastic deformation zone, i.e. cone of fines, under contact area. If the rate of strain is sufficient to increase this cone volume to a critical level, tensile stresses prevail around the contact circle, forming and propagating meridian cracks [12] which fracture the solid like slices of orange. It should also be emphasized that either secondary or branching cracks, commonly perpendicular to the meridian fractures, may form just after the completion of meridian cracks $[6,7,13]$. When the applied strain rate is further increased, the cone of fines become, larger and oblique/radial cracks replace meridian cracks. As a result, fine fragments and a coherent large cone formed. The large coherent cone becomes gradually shorter and narrower with increasing strain-rate [1]. If the strain rate is excessive, failure fronts are said to propagate throughout the particle, leading to either intense

${ }^{a}$ Corresponding author: mcamalan@metu.edu.tr 
fragmentation or shattering with no large, coherent fragments left [1, 11]. Although the shattering mechanism has not been explicitly defined in the literature, this may be physically similar to failure of brittle solids observed under very high compressive loads where failure waves reduced spall (tensile) and shear strength of brittle material, drastically causing inelastic, shear-induced micro-cracking [1416]. King [17] defines the breakage mode "shattering" as a series of fracture steps, induced by a rapid application of compressive stress, in which there is a sequential re-breakage of successive generations of daughter fragments until all of the energy available for fracture is dissipated. However, re-breakage events have not been sufficiently elucidated within the context of single-particle studies because of the difficulty in monitoring the fragmentation sequence in an extremely short duration of impact loading. There might still be some indirect evidence from those studies that could be linked to re-breakage. For example, the reason for the secondary crack formation was related to the unbalanced stresses in highvelocity, single-particle impact [6,7] and to the continued loading on meridian-fracture-related fragments by compression tester $[1,10]$. Therefore, despite the limited information, it may be possible that the aforementioned breakage patterns inherently include re-breakage events. Kapur et al. [18] also supported re-breakage of progeny particles and stated that re-breakage at high impact energy levels provide self-similar product size distributions.

Although the abovementioned studies widely explain the breakage phenomena of brittle solids, there is generally lack of clear mathematical relations between any breakage mode and its corresponding fragment distribution. The objective of this paper is to find qualitative evidences for the modes of breakage mentioned above, through impact-related breakage parameters and self-similar progeny distributions. For this purpose, drop-weight tests were performed on six single-size classes (particle sizes ranging from 25.4 to $3.35 \mathrm{~mm}$ ) of Portland cement clinker. Each size class was stressed with various impact energy levels, and the corresponding product size distributions of each energy level were decomposed to breakage probability and progeny size distributions, both in discrete and cumulative forms, for further evaluation.

\subsection{Breakage probability and breakage function}

For any given single-size class of particles, two important breakage parameters can be generated from the product size distributions of single-particle impact: (a) breakage probability and (b) breakage function. The former can be defined as the cumulative mass fraction of single-size particles which are broken upon application of a specific impact energy $(\mathrm{J} / \mathrm{g}, \mathrm{kJ} / \mathrm{kg}$ or $\mathrm{kWh} / \mathrm{t})$. Impact breakage function can be represented in two different forms: the discrete breakage function, denoted as $b_{i 1}$, and the cumulative breakage function, denoted as $B_{i I}$. The former is the mass percentage (or fraction) of material broken from a single-size feed (indexed as ' 1 ') which, upon breakage, goes to a finer size interval ' $i$ ':

$$
b_{i 1}=p_{i} / P_{2} \text {, where } i>1
$$

where $p_{i}$ is the mass percentage of product retained in size class ' $i$ ', and $P_{2}$ is the cumulative mass percentage of breakage product passing from the upper sieve of size interval ' 2 '. Equation 1 can be graphically shown by plotting $b_{i 1}$ values against the geometric mean sizes of the corresponding intervals ' $i$ '. This function represents the discrete size distribution of progeny particles. The cumulative breakage function, $B_{i l}$, is the cumulative mass fraction of progeny fragments broken from size 1, which appears less than the upper size of size interval ' $i$ ':

$$
B_{i 1}=P_{i} / P_{2} \text {, where } i>1
$$

where $\mathrm{Pi}$ is the cumulative mass percentage of materials passing from the upper sieve of size interval ' $i$ '. Obviously, this will yield the cumulative size distribution of progeny particles. Equation 2 can be graphically represented by plotting each $B_{i l}$ value against the corresponding upper sieve size of size interval ' $i$ '. 


\section{Materials and methods}

Six size fractions $(-25.4+19.0,-19.0+12.7,-12.7+9.53,-9.53+6.35,-6.35+4.7$ and $-4.7+3.35 \mathrm{~mm})$ of Portland cement clinker were used as the experimental material. The oxide contents of each size fractionswere measured by a Spectro IQ X-ray fluorescence (XRF) spectrometer and the results are given in Table 1. These results showed that the chemical compositions of the tested size classes were very similar, inferring material homogeneity in all of the tested size fractions.

Table 1. Chemical composition of the experimental single-size clinker fractions.

\begin{tabular}{|c|c|c|c|c|c|c|}
\hline \multirow{2}{*}{$\begin{array}{c}\text { Clinker } \\
\text { Constituents }\end{array}$} & \multicolumn{7}{|c|}{\begin{tabular}{c} 
Percentage in the size fractions \\
\cline { 2 - 7 }
\end{tabular}} & $\begin{array}{c}\mathbf{- 2 5 . 4 + 1 9 . 0} \\
\mathbf{m m}\end{array}$ & $\begin{array}{c}\mathbf{- 1 9 . 0 + 1 2 . 7} \\
\mathbf{m m}\end{array}$ & $\begin{array}{c}\mathbf{- 1 2 . 7 + 9 . 5 3} \\
\mathbf{m m}\end{array}$ & $\begin{array}{c}\mathbf{- 9 . 5 3 + 6 . 3 5} \\
\mathbf{m m}\end{array}$ & $\begin{array}{c}\mathbf{- 6 . 3 5 + 4 . 7} \\
\mathbf{m m}\end{array}$ & $\begin{array}{c}\mathbf{- 4 . 7 + 3 . 3 5} \\
\mathbf{m m}\end{array}$ \\
\hline $\mathrm{CaO}$ & 66.39 & 65.51 & 67.35 & 64.62 & 67.78 & 64.93 \\
\hline $\mathrm{SiO}_{2}$ & 19.12 & 19.77 & 18.59 & 20.02 & 17.35 & 20.33 \\
\hline $\mathrm{Fe}_{2} \mathrm{O}_{3}$ & 3.62 & 3.62 & 3.82 & 3.53 & 3.63 & 3.69 \\
\hline $\mathrm{Al}_{2} \mathrm{O}_{3}$ & 5.13 & 5.56 & 4.62 & 5.82 & 5.36 & 5.75 \\
\hline $\mathrm{SO}_{3}$ & 1.59 & 1.33 & 1.51 & 1.31 & 1.34 & 1.26 \\
\hline $\mathrm{MgO}$ & 2.28 & 2.37 & 2.03 & 2.43 & 1.32 & 2.43 \\
\hline $\begin{array}{c}\mathrm{LOI}(L o s s- \\
\text { on-Ignition) }\end{array}$ & 0.02 & 0.01 & 0.01 & 0.01 & 0.02 & 0.01 \\
\hline
\end{tabular}

The drop-weight test was used to perform single-particle breakage tests. The test consists of dropping a cylindrical steel weight from a known height to a single particle placed on a steel base plate. The specific impact energy $E_{i s}(\mathrm{~kJ} / \mathrm{kg})$ imparted on to a single-size class of particles can be determined by varying the drop weight and the drop height using Eq. 3.

$$
\text { Eis }=\left[0.00981 \cdot M \cdot\left(h_{0}-h_{f}\right)\right] / m
$$

where $M$ is the mass of the drop weight $(\mathrm{kg}), h_{0}$ is the initial drop height (mm) measured from the surface of anvil to the bottom of the drop weight, $h_{f}$ is the offset height $(\mathrm{mm})$ between the bottom of the drop weight and surface of the anvil after impacting on the particle, and $m$ is the average weight of a particle in the set of tested particles $(\mathrm{g})$. For each experiment, 1, 2 or $20 \mathrm{~kg}$ drop-weights along with drop-heights ranging from 0.03 to $1 \mathrm{~m}$ were used to produce a wide range of $E_{i s}$. The experimental set of specific impact energies and the number of particles stressed for each size class is given in Table 2 .

Table 2. $E_{i s}$ levels and the number of particles stressed for each sample class.

\begin{tabular}{|c|c|c|}
\hline Fracions $(\mathbf{m m})$ & $\boldsymbol{E}_{\boldsymbol{i} \text { }} \mathbf{( k J / k g )}$ & Number of particles stressed \\
\hline$-25.4+19.0$ & $0.04,0.18,0.40,0.79,1.48,2.12,3.17,4.46,6.26$ & $20-50$ \\
\hline$-19.0+12.7$ & $0.11,0.22,0.40,0.79,1.58,3.17,6.44,8.89$ & $150-180$ \\
\hline$-12.7+9.53$ & $0.11,0.40,0.79,1.58,2.23,3.17,5.40,6.12,9.18$ & $100-200$ \\
\hline$-9.53+6.35$ & $0.36,0.79,1.98,3.31,7.96,15.66$ & $200-250$ \\
\hline$-6.35+4.7$ & $0.83,1.62,3.17,6.26,12.24,18.36,24.77$ & $250-350$ \\
\hline$-4.7+3.35$ & $1.94,3.92,7.85,11.95,17.68,24.08,27.40$ & $300-350$ \\
\hline
\end{tabular}




\section{Results and discussion}

Figure 1 shows the distribution of discrete breakage functions for all of the size classes at a range of specific impact energies. The distributions are left-skewed (the long tail on the left) with a distinct major peak located at the coarse end of the breakage product size range. The peak becomes shorter and wider, and shifts towards the finer sizes with an increase in the specific energy input. From the fragmentation pattern viewpoint, the sequential transition from meridian/secondary cracks to oblique/radial cracks and shattering adequately explains this variation in the shape of the distributions since the meridian/secondary cracks forming at low specific energy inputs are expected to give mainly a few coarse fragments of similar size. Whereas oblique/radial cracks and shattering at relatively higher energy inputs are expected to produce many fragments having a wide size range. In fact, a similar variation in the fragment size distribution was also observed by Salman et al. [19] in the transition from low to high velocity impact fragmentation of aluminum oxide particles.

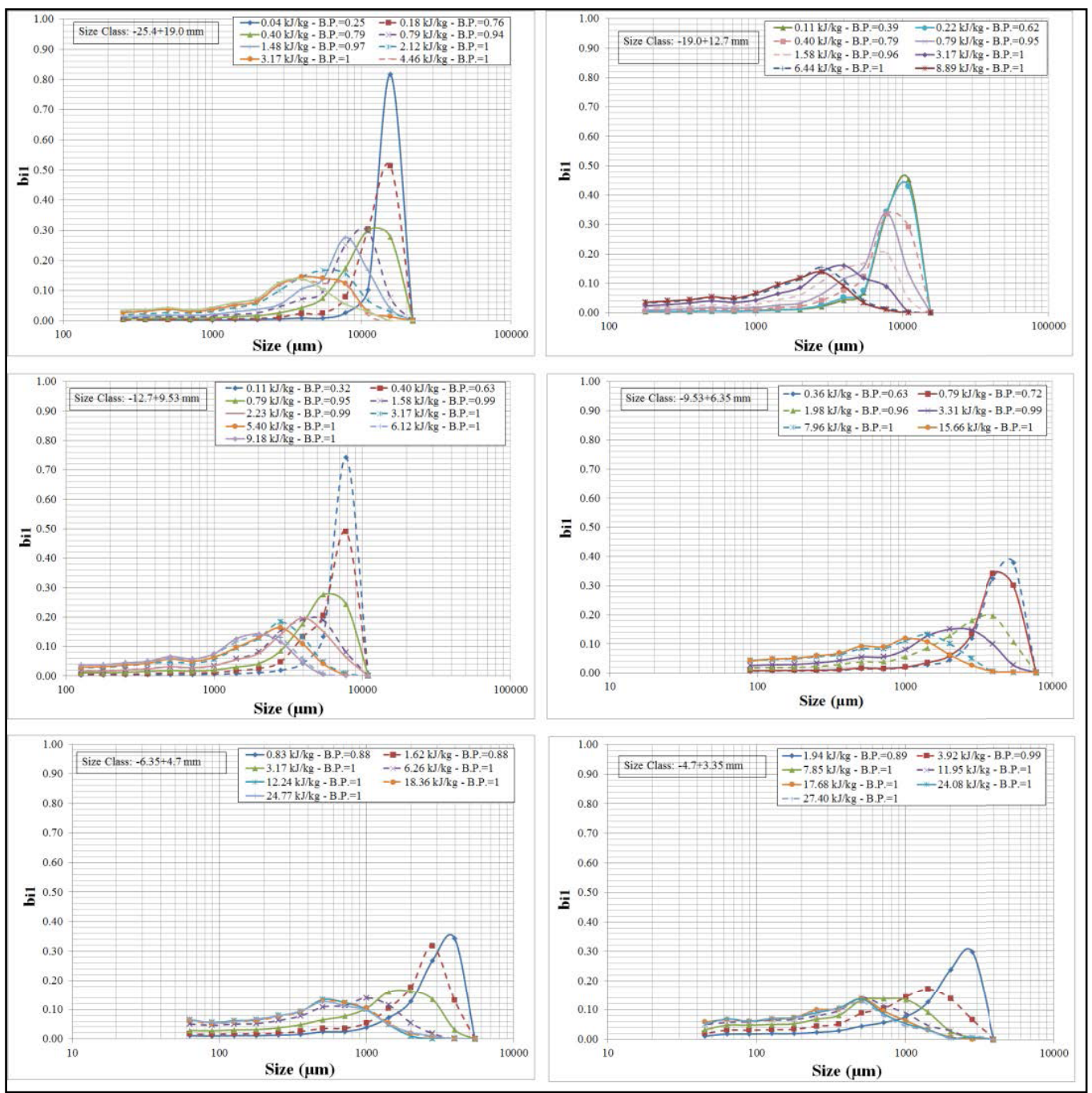

Figure 1. Discrete breakage functions of all size classes. B.P.= breakage probability. 
Figure 2 also shows that the discrete breakage functions $\left(b_{i l} s\right)$ approach a limiting distribution around $500 \mu \mathrm{m}$, irrespective of the parent particle size if the specific energy input is increased above $12 \mathrm{~kJ} / \mathrm{kg}$. The limiting distribution may arise by the following reasons: First, the progeny will become so small that successive fracturing might be difficult. Interestingly, Yashima et al. [20] reported in an earlier study on single-particle impact breakage of natural materials that the specific fracture energies increased rapidly for particles less than $500 \mu \mathrm{m}$. Secondly, successive breakage events eventually form a pile of fragments between the flat surfaces of the anvil and the drop weight, such that particlebed breakage, rather than single-particle breakage, prevails either during the later stages of the primary impact or during the impacts after rebounds of the drop weight.

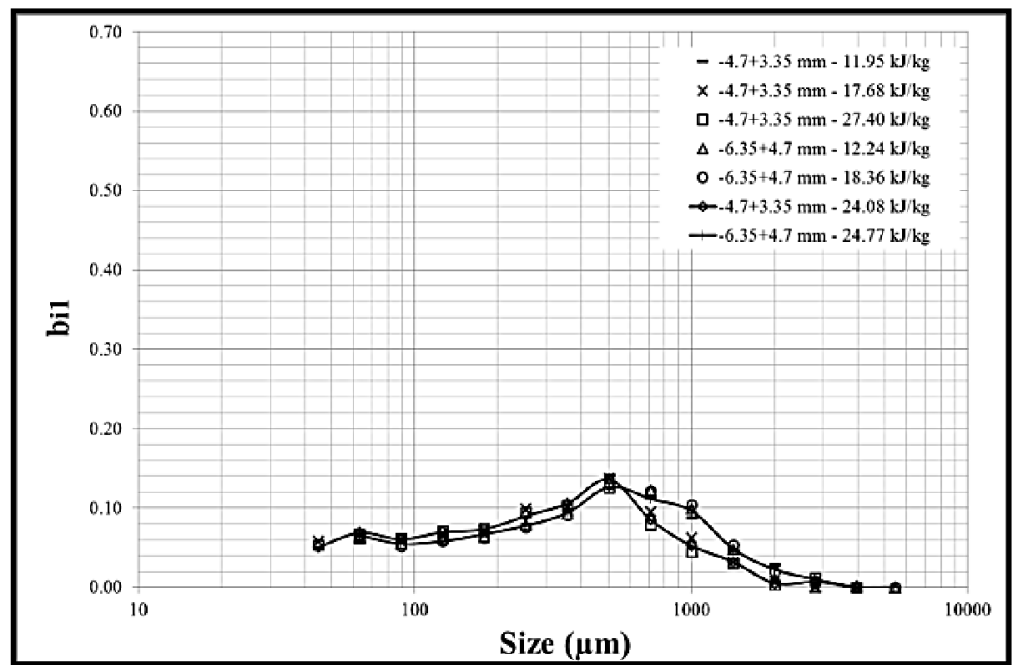

Figure 2. The discrete breakage functions remaining fixed for the specific energy inputs higher than $12 \mathrm{~kJ} / \mathrm{kg}$.

As the mode of breakage for a single particle is dependent to a large extent on the applied impact energy, it seems logical that the size distribution of progeny fragments must be non-similar depending on the mode of breakage the mother particle undergoes. Still, it is noteworthy that even though the mother particle size is different, the size distributions of progeny fragments change in the same manner (Figure 1). This brings out the question whether a particle, irrespective of its size, will pass through the same, distinct modes of breakage (from meridian cracking to oblique/radial cracks and shattering) as the breakage energy increases. A graphical means of testing this could be to plot a set of cumulative breakage functions obtained at different levels of the impact energy against a normalized size, that is, a particle size rescaled by the median fragment size $\left(d_{50}\right)$ of the breakage function. If these set of normalized curves from such plots fall onto either the same curve or a narrow band, then the distributions are called self-similar reflecting similar breakage patterns [21]. Figure 3 shows semi-logarithmic plots of cumulative breakage functions against the normalized size for the whole set of drop-weight breakage data obtained under various combinations of mother particle size and applied specific impact energy. The plots show that the cumulative breakage functions are non-similar, indicating different breakage patterns depending on the prevailing breakage mode. However, if the data are re-plotted in groups of similar breakage probabilities (Figure 4), we obtain self-similar distributions regardless of mother particle size and the specific impact energy, indicating similar breakage patterns. In fact, this finding was previously supported by Vogel and Peukert [22] such that the similar breakage pattern leads to the same breakage probability for geometrically similar and physically identical particles. 


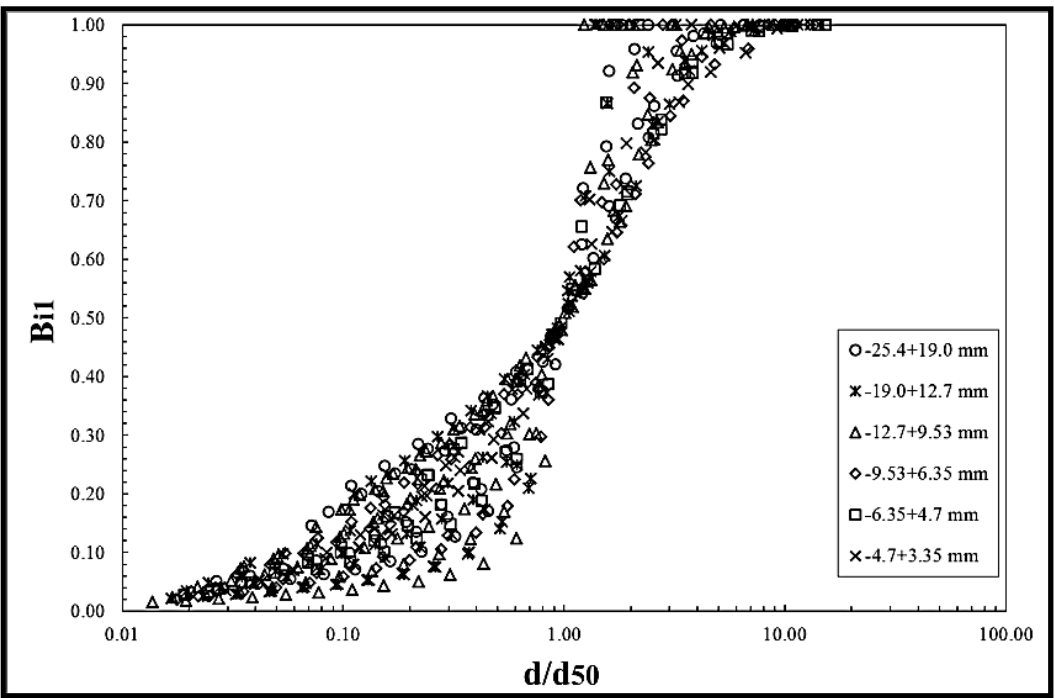

Figure 3. Normalized cumulative breakage functions of all size-classes at different impact energy levels.

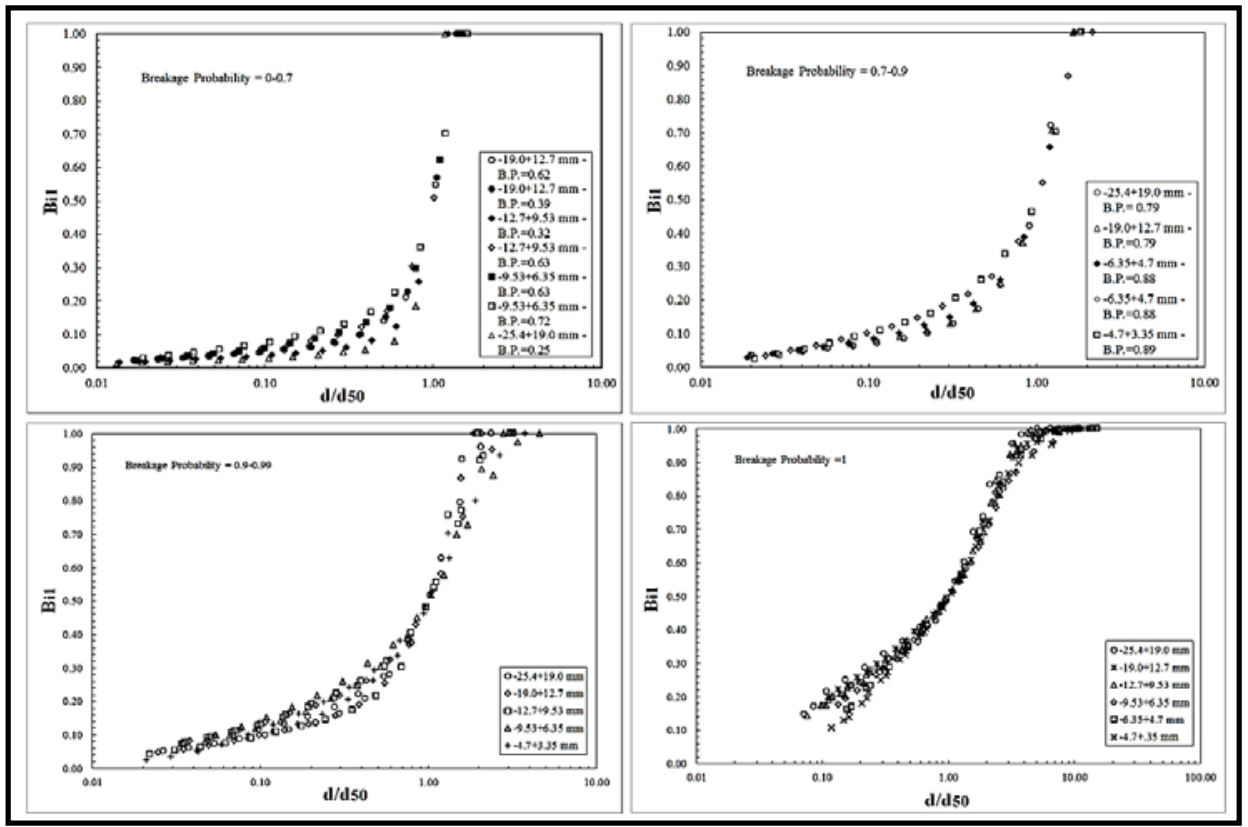

Figure 4. Normalized cumulative breakage functions of all size-classes re-plotted in groups of different breakage probabilities (B.P.= Breakage Probability).

\section{Conclusions}

Single particle breakage of cement clinker particles produces different progeny distributions or breakage functions where the change in their shapes shows evidence for the distinct modes of breakage (meridian cracks to oblique/radial cracks and shattering). Irrespective of the mother practice size, the shapes of the discrete breakage function distributions approach a limited distribution for specific energies higher than $12 \mathrm{~kJ} / \mathrm{kg}$, irrespective of the mother particle size. Self-similar, impact- 
related progeny size distributions can only be achieved if the particles either have the same breakage probability for any energy input or they are broken in the same mode of breakage.

\section{References}

1. D.A. Gorham, A.D. Salman. Wear 258, 580 (2005)

2. D.G. Papadopoulos, PhD thesis (University of Surrey,1998)

3. S. Middlemiss, Int. J. Miner. Process., 84, 207 (2007)

4. D.G. Papadopoulos, M. Ghadiri, Adv. Powder Technol., 7, 183 (1996)

5. K. Schönert, Powder Technol., 143-144, 2 (2004)

6. W. Schubert, M. Khanal, J. Tomas, Int. J. Miner. Process, 75, 41 (2005)

7. M. Khanal, W. Schubert, J. Tomas, Int. J. Miner. Process, 86, 104 (2008)

8. S. Antonyuk, J. Tomas, S. Heinrich, L. Mörl, Chem. Eng. Sci., 60, 4031 (2005)

9. J. Subero, M. Ghadiri, Powder Technol., 120, 232 (2001)

10. S.Z. Wu, K.T. Chau, T.X. Yu, Powder Technol., 143-144, 41 (2004)

11. E.W. Andrews, K.-S. Kim, Mech. Mater., 31, 689 (1999)

12. M.M. Chaudhri, Powder Technol., 143-144, 31 (2004)

13. S. Antonyuk, M. Khanal, J. Tomas, S. Heinrich, L. Mörl, Chem. Eng. Prog., 45, 838 (2006)

14. R.J. Clifton, Appl. Mech. Rev., 46, 540 (1993)

15. N. Bourne, J. Millett, Z. Rosenberg, N. Murray, J. Mech. Phys. Solids, 46, 1887 (1998)

16. D.D. Radford, G.R. Willmott, S.M. Walley, J.E. Field, in Proceedings J. de Physique IV, 110, 687 (2003)

17. R.P., King, Modeling and Simulation of Mineral Processing Systems (Oxford: ButterworthHeinmann Publications, 2001)

18. P.C. Kapur, D. Pande, D.W. Fuerstenau, Int. J. Miner. Process, 49, 223 (1997)

19. A.D. Salman, C.A. Biggs, J. Fu, I. Angyal, M. Szabo, M.J. Hounslow, Powder Technol., 128, 36 (2002)

20. S. Yashima, Y. Kanda, S. Sano, Powder Technol., 51, 277 (1987)

21. D.W. Fuerstenau, P.C. Kapur, Powder Technol., 82, 51 (1995)

22. L. Vogel L, W. Peukert, Powder Technol., 129, 101 (2003) 